\title{
THREE DIMENSIONAL CITY BUILDING MODELLING WITH LIDAR DATA (CASE STUDY: CIWARUGA, BANDUNG)
}

\author{
Hudan Asharyanto ${ }^{1}$, Budhy Soeksmantono ${ }^{2}$, and Ketut Wikantika ${ }^{2}$ \\ ${ }^{1}$ Center for Remote Sensing, Institut Teknologi Bandung (ITB), Bandung, Indonesia, \\ Email:hudanasharyanto@yahoo.com \\ ${ }^{2}$ Remote sensing and GIS Research Group, Institut Teknologi Bandung (ITB), Jl. Ganesha 10, \\ Bandung 40132, West Java, Indonesia \\ Email: soeksmantono@gd.itb.ac.id, ketut@gd.itb.ac.id
}

KEY WORDS: Light Detection and Ranging, 3D model, Building, DTM, DSM, Orthophoto

\begin{abstract}
As one of the metropolitan cities in Indonesia, Bandung has many kinds of existing buildings. According to that fact, LIDAR or Light Detection and Ranging technology can be used to create good and accurate urban planning system needed to see spreading of existing building. It is used because it scans the area quickly and accurately. In addition, Orthophoto is used to increase the accuracy of the information from the model. These data will be processed into surface model and three-dimensional building model. The coverage area of this study is 222 hectare with 678 are the building blocks. As a result, model is divided into three categories based on the size and distance of proximity between one building to another. From the results, 250 buildings model which are in category A and B can be modeled very well and the rest of the category C it was unable to create a good building model or fracture appears on the model due to the building blocks of those area are too dense.
\end{abstract}

\section{INTRODUCTION}

Bandung is the one of metropolitan city in Indonesia, which owns the building are many and varied. Due to many types of buildings standing, then need for good urban planning system. It took a thorough and detailed planning of the layout of the city. There are many technologies that can be used to modeling a city building system, with high accuracy and efficiency. One technique that produces model with a high accuracy is to use remote sensing technology, such as Light Detection and Ranging (LIDAR) and photogrammetry. LIDAR data has an accuracy of DEM (Digital Elevation Model) and orthophoto that has good planimetric accuracy, it will be processed into a 3D model that can be used for many purposes. In this research the aims is to create a 3D building model with Bandung as study area. In the previous research, there are the methods to city building modeling from different data source, such as getting DTM and DSM of buildings and land surface model extraction from high-resolution satellite imagery data (Tack, 2012), stereo image of photogrammetry can also be used as a method to accurately reconstruction of building model (McClunea, 2014). There are also combine multiple types of data such as satellite imagery, LIDAR and aerial photographs as well as to create a model of the existing building with the approach of quantitative evaluation (Moreira, 2013). This 3D model is expected to be used in decision making at an urban planning system.

\section{MATERIAL AND METHOD}

\subsection{Light Detection and Ranging (LIDAR)}

LIDAR, or Light Detection and Ranging is a remote sensing system with active sensors which measure the reflection of light to find range and distance from a target of (Measures, 1984). LIDAR has a good efficiency and validity as a source of data for the height of the earth terrain. (Center, 2012). LIDAR is widely used for the construction of three-dimensional objects such as roads, railways, bridges, buildings, and other infrastructure (Center, 2012). LIDAR has three main components, the laser sensor, GPS (Global Positioning System), and IMU (Inertial Measuring Unit). It has ability to emit laser 150000 pulses per second with a variation of the scan angle from of $1^{\circ}$ to $75^{\circ}$. Laser wave pulses emitted continuously, can be recorded up to five reflectance per pulse emitted from the object on the earth surface. LIDAR laser sensor emits near infrared waves with a wavelength of $1064 \mathrm{~nm}$ (Center, 2012). Figure 1 shows illustration of the working principle of LIDAR. 


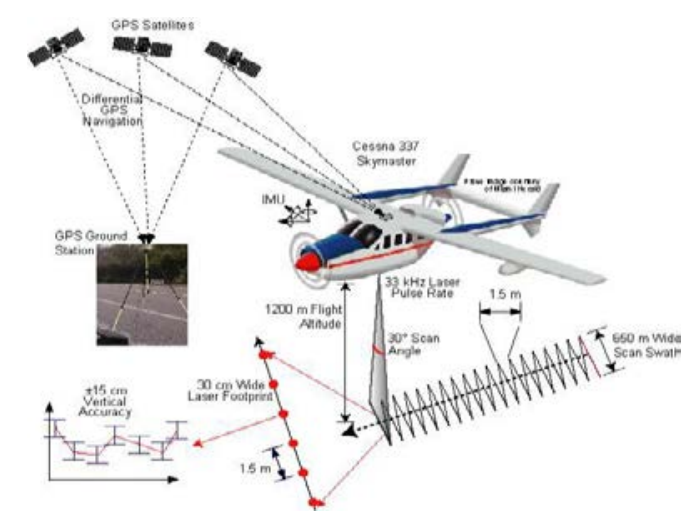

Figure 1. Illustration of airborne LIDAR works (lidar.ihrc.fiu.edu)

The difference time between when the laser beam is emitted and when the laser beam received by the optical receiver is calculated LIDAR data and convert it data into a measurable distance (Center, 2012)):

$$
\mathrm{D}=\mathrm{c} . \Delta \mathrm{t} / 2
$$

In equation (1), D is the distance between the sensor and the object being measured, $\mathrm{c}$ is the speed of light, and $\mathrm{t}$ is the distance of the signal. Amount of the resulting point cloud data is 1-9 points $/ \mathrm{m}^{2}$. Vertical accuracy of LiDAR data is less than $20 \mathrm{~cm}$ and 30-50 cm for the horizontal is in the range of 15-24 cm and 30-64 cm for horizontally (Center, 2012).

\subsection{Surface Model}

Digital Terrain Model (DTM) is a digital representation (numerical) from ground level is as known coordinates x, y, and z (Li, Zhu, \& Christopher, 2005) or more details, defined as a discrete representation of a surface topography or collection of discrete points (xi, yi, zi) in the space coordinate system that represents a physical three-dimensional surface (Dipokusumo, 2010). In this research, DTM is a representation of the point cloud data at the ground class. All data on ground classes will be generated into a DTM.

Digital Surface Model (DSM) is a digital representation (numeric) object above the ground is known coordinates $\mathrm{x}$, y, and $\mathrm{z}$ (Li, Zhu, \& Christopher, 2005). Representation of the object on the above surface can be in the form of buildings, vegetation, and other objects. DSM is the point clouds on the first-return. The object is usually a first-return usually is the roof of the building, a canopy of trees, towers, and others. In the present research the representation of the DSM is building a class that is the object of the roof of a building. Illustration term DSM and DTM can be seen in Figure 2.

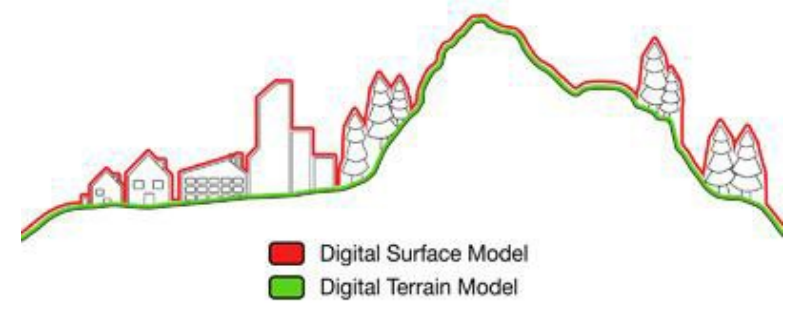

Figure 2. Illustration DSM and DTM

\subsection{Data and Study Area}

The data in this study derived from PT Karvak Nusa Geomatics Karvak which acquired in May 2013. The data are .LAS format consisting of point clouds and still raw (not classified). The density of the data is $\pm 2-3$ points / $\mathrm{m}^{2}$. This study area is the District Ciwaruga, West Bandung Regency, District Isola, Bandung, and the District of North Cimahi, Cimahi. Figure 3 shows the location of the research from a photograph and Table 1 shows the specification of LIDAR data and coordinate. The study area is contain many kind of building such as Setra Duta residence, Bandung State Polytechnic (POLBAN), and other residential housing. In the red circles represent luxury residential building, orange circles represent large buildings with close distance between each other, and yellow circle represents the building with dense housing. 
Table 1. Spesification of LIDAR data

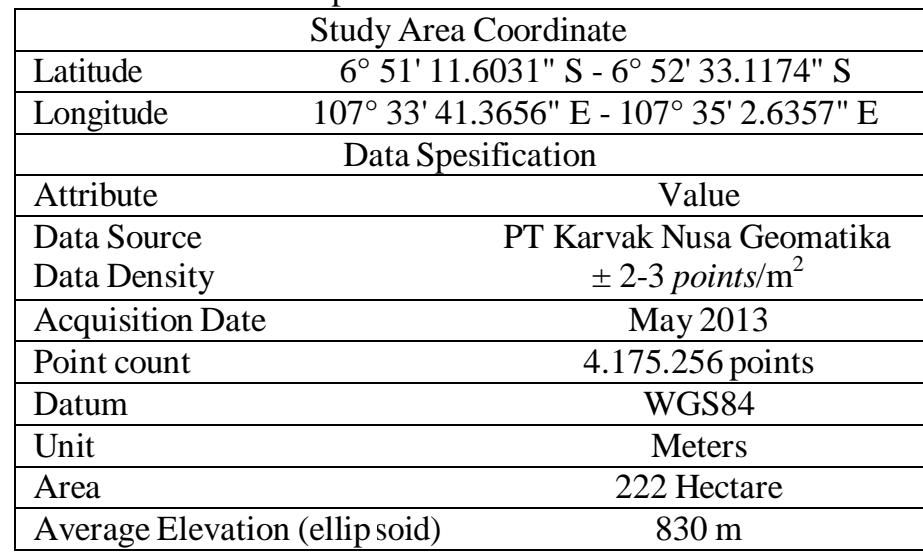

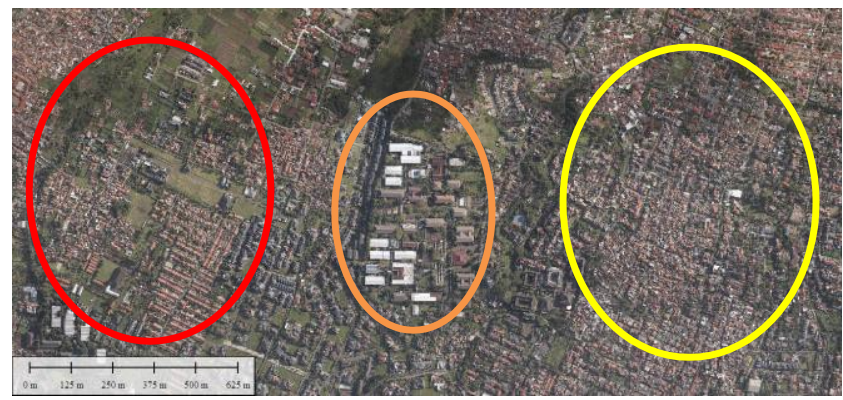

Figure 3. Orthophoto of Study Area

\subsection{LIDAR Data Processing}

\subsubsection{Ground}

The first step is ground class classification to separate between ground class and non-ground class. In this classification, TerraSolid use Adaptive TIN Models method (Axelsson, 2000). Illustration approach this method can be seen in Figure 4.

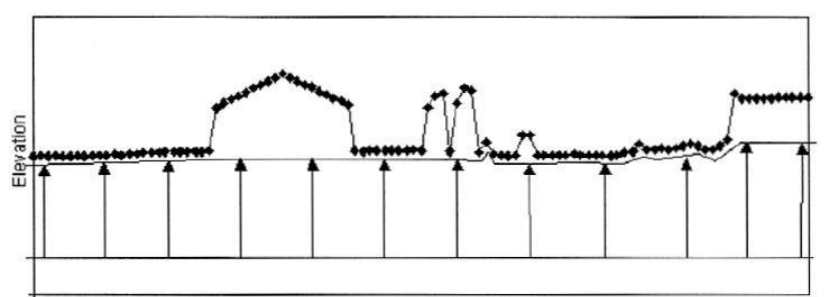

Figure 4. Connecting TIN surface with laser data (Axelsson, 2000)

Surface adapts with the existing distribution point and the new point which is meets certain data derived from the threshold parameter. Parameter threshold is estimated from the data and the changes during the filtering process. The algorithm is a repetitive process where the TIN is composed of starting point clouds.

\subsubsection{Building}

After the classification of ground class has been done, the next step is a building class classification. Algorithm is look at the distribution of the data which is plane form above the ground class. (Vosselman, 1999). Illustrations distribution point clouds that form a field can be seen in Figure 5. 

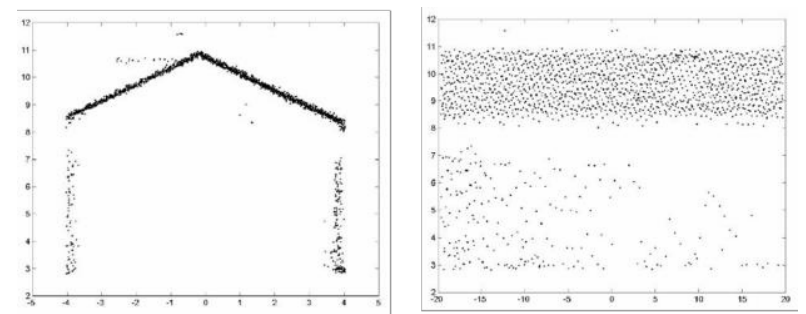

Figure 5. Building class data distribution (Vosselman, 2001)

\subsection{D Building Modelling}

After classification appropriate to the class, next step is reconstruction of building model. The main processes related to three-dimensional modelling are detection of planar roof faces, intersection of roof faces, determination of roof outline. (Mass and Vosselman, 1999).

\subsubsection{Detection of planar roof faces}

Detection have the purpose to determine the cluster of each face of the plane. Clustering process based on the formation of TIN in plane of the roof. All TIN which is part of the same roof face is a group of the same plane. 3D Hough Transform (Hough, 1962) used to describe the two slope and distance parameters. The equation can be seen in equation (2).

$$
Z=s_{x} X+s_{y} Y+d
$$

$\left(s_{X} X, s_{Y} Y\right)$ shows the slope in the direction of $x$ and $y$, while $d$ is the vertical distance from the plane to the surface of ground. Each point $(X, Y, Z)$ in the data set defines plane on the cluster. Then a point in the same cluster will be create TIN and the candidates of the roof of a model as shown in Figure 6.

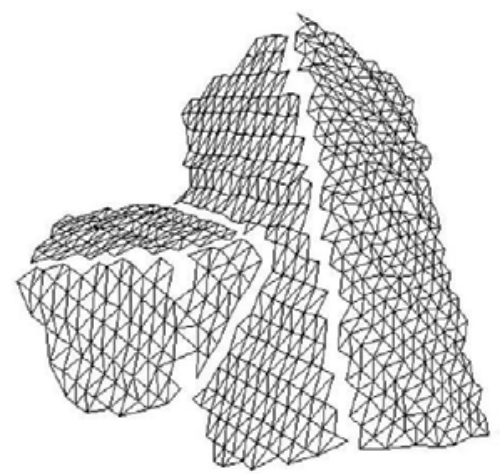

Figure 6. Creating Roof Model with TIN (Mass dan Vosselman, 1999)

\subsubsection{Intersection of Roof Faces and Determination of Roof Outline}

There are two major lines in the intersection face, the first is to combine intersection of the roof edge which is in different clusters and the edge of intersection directly with another object or so-called roof frame. Illustration intersection of the roof face can be seen on the red circle and the determination of the roof frame on the blue circle in Figure 7. To combine the intersection between the edge of the roof on each cluster defined first intersection which contains a point which is located on the boundary between clusters. From those point boundary which is at the edge of the cluster will be connected to the next cluster. After all clusters are connected to each other roof next process is the formation of the roof frame, the roof of which is already connected can be seen in the left pictuire at Figure 8. In the picture is the roof edge does not represent the outline of the roof building, therefore it must approximation to approach the edge of the roof. The method used the Douglas-Peucker algorithm in 1973. The working process of this method is to reduce the number of pint formed into a curve, so that the result curve is only approximated by a series of points only. Results of the roof edge can be seen in the middle picture at Figure 8. 


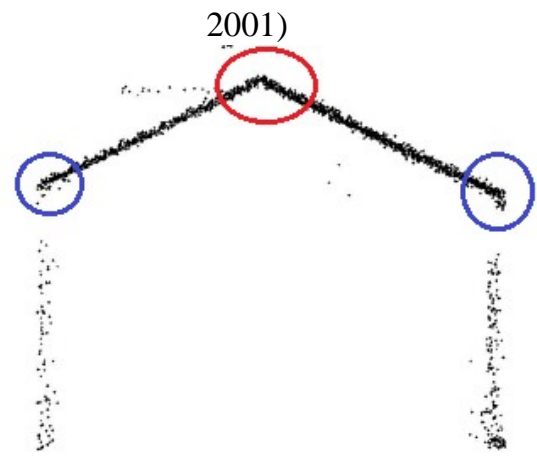

Figure 7. Illustration of Intersection The Each Roof Faces Edge (side view) (Vosselman,

The method to adjust the roof edge is often used the least squares. The adjustment results can be seen in the right picture at Figure 7 which is represent a model of the roof.
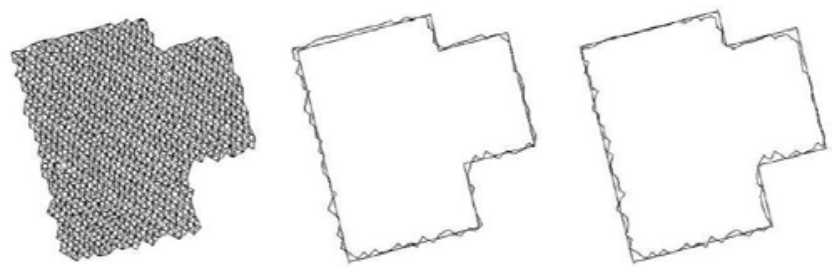

Figure 8 Illustration of Roof Model Approximation (Mass and Vosselman, 1999)

\subsubsection{Reconstruction of Roof Model}

The result of making the roof models can be seen in Figure 9. In general, airborne LIDAR have not get information of a building wall. Due to the laser wave is not reach the wall. Therefore, it is assumed that the wall is elevation from the intersection of the roof edge to the ends of the ground.

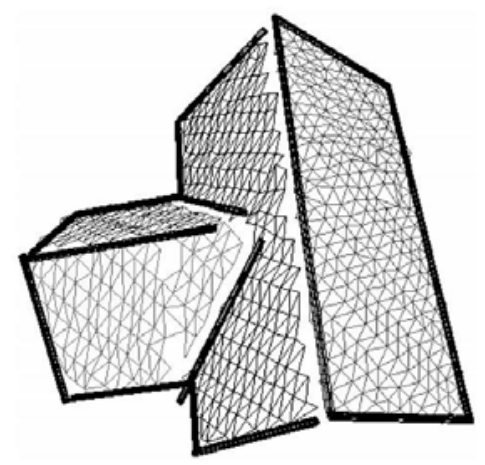

Figure 9. Final Result of Roof Reconstruction (Maas and Vosselman, 1999)

\subsection{Research Methodology}

The research methodology used in this study starts from LIDAR data collection in the form of point cloud and orthophoto processes to be used in building a model city. The LIDAR data through the classification process to separate classes of natural objects according to their original appearance on earth. This classification is composed of two phases, semi-automatic classification and manual classification. Semi-automatic classification is a classification method using an algorithm and paramater to solve classification. After generating classes using these methods, then performed a manual process point cloud classification to classify the unclassified and the class is not in accordance with the state of the earth actually in the process of semi-automatic classification. Main class used is ground and building class. Point cloud to be processed into a DTM (Digital Terrain Model) whereas the cloud point in building a class that will be created three-dimensional model. Point cloud in the building class will be made of three-dimensional building model with extraction vectorize building. Once created three-dimensional model, then performed overlaying with orthophoto to be checked whether the object in accordance with the circumstances actually or not. 


\section{RESULT AND DISCUSSION}

\subsection{Result of LIDAR Data Procesing}

\subsubsection{Result of Point Clouds Classification}

Figure 10 shows classification results of ground class. The Dark brown points is the class ground

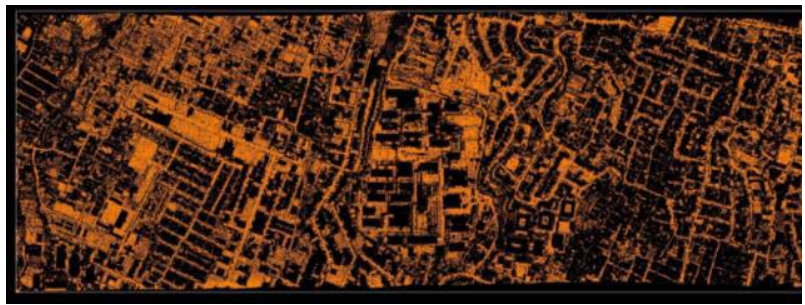

Figure 10. Result of Ground Class Classification

Figure 11 shows the result of building class classification. As I have mentioned to make building class, ground class already as a reference. Figure 12 shows the data that has been classified into building and ground class.

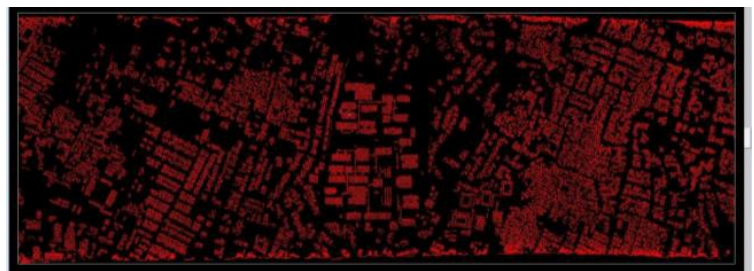

Figure 11. Result of Building Class Classification

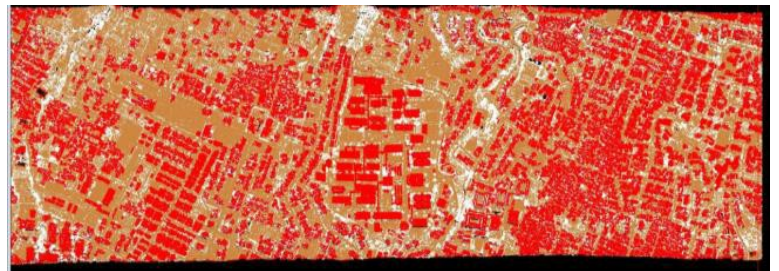

Figure 12. Overlay Between Ground and Building Class

\subsubsection{Result of 3D Building Modelling}

The next process is to reconstruction a model of the building with the results of the building class points. Figure 13 shows the result of automatic building model reconstruction. Result of automatic building model reconstruction is not always appropriate with the existing situation in the field. It must be check the existing building models manually with orthophoto in the same area. Figure 14 shows an example of a building checking of the model suitability with the orthophoto

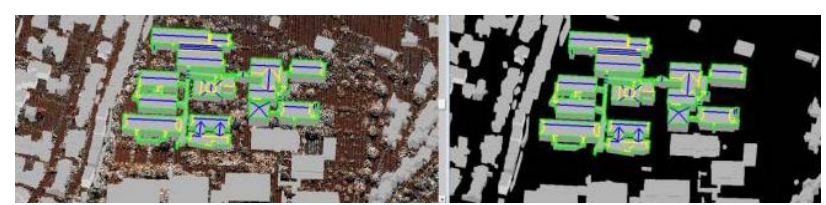

Figure 13. Result of Building Reconstruction Figure
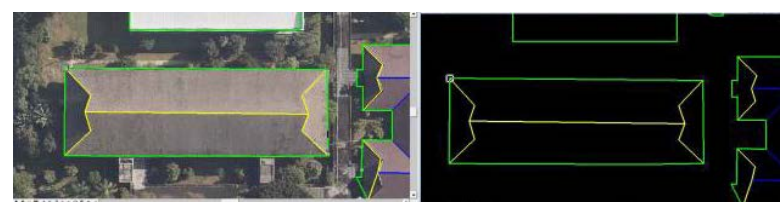

14. Checking of Model with Orthophoto

From the results of these building blocks is obtained building blocks are sutability with the original state. Figure 15 shows an example of a building that has been checked.

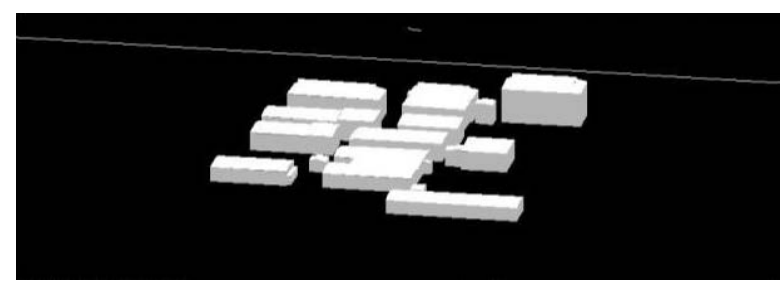

Figure 15. Result of Building Model After Manual Checking

\subsection{Building Model Category}

From the study area there are three categories of building types that are modeled, such as; 


\subsubsection{Category A}

The building is large and far apart with another building (Category A).This category has dimensions of length 67 $\mathrm{m}$, width $24 \mathrm{~m}$, height of $14.5 \mathrm{~m}$, the distance between another buildings $13 \mathrm{~m}$. There are 30 building blocks that are in this category. Figure 16 illustrate examples of buildings that represent these categories.

\subsubsection{Category B}

The building of medium size and quite close to another buildings (Category B). This category has dimensions of length $34 \mathrm{~m}$, width $21.5 \mathrm{~m}, 16.5 \mathrm{~m}$ high, and $9.5 \mathrm{~m}$ distance between buildings. There are 220 building blocks that are in this category. In Figure 17, illustrated examples of buildings that represent these categories.

\subsubsection{Category C}

The building is small and close to another buildings (Category C).This category has average dimensions of length $7.5 \mathrm{~m}$, width $7.5 \mathrm{~m}$, height $7 \mathrm{~m}$, and the distance between the building does not exist because it coincides with another building. There are 428 building blocks in this category. Figure 18 illustrate examples of buildings that represent these categories.

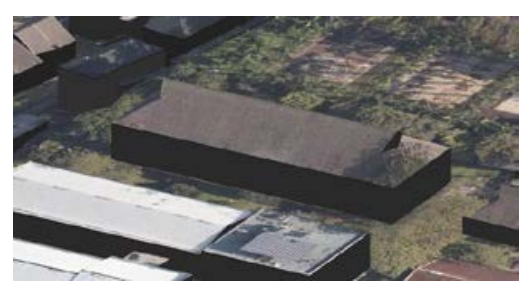

(a)

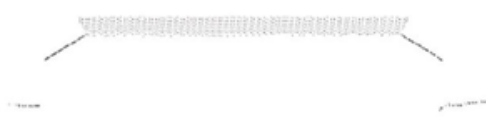

(d)

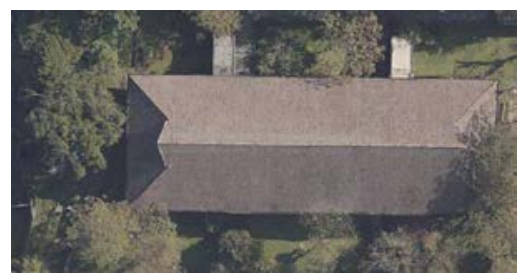

(b)

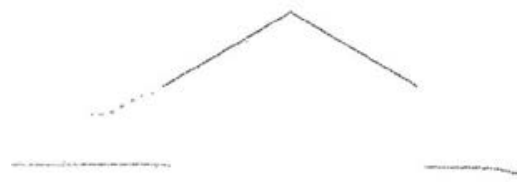

(c)

Figure 16. (a) Sample Building Model in Category A. (b) Two Dimension Orthophoto of Category A. (c) Point Clouds of Category A Building Roof (Front View). (d) Point Clouds of Category A Building Roof (Side View)

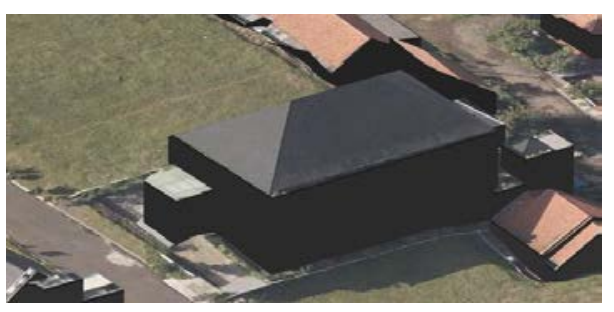

(a)

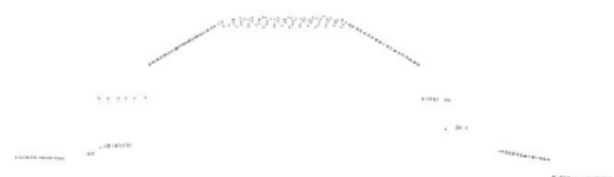

(d)

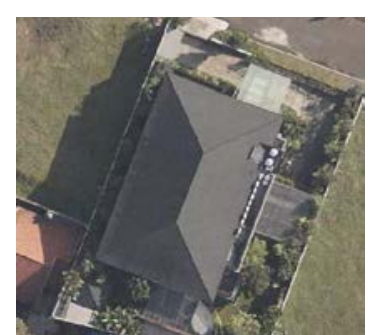

(b)

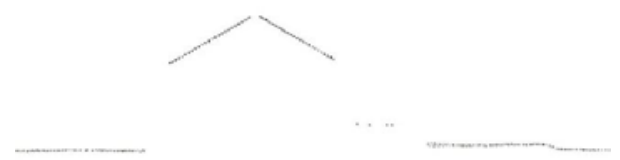

(c)

Figure 17. (a) Sample Building Model in Category B. (b) Two Dimension Orthophoto of Category B. (c) Point Clouds of Category B Building Roof (Front View). (d) Point Clouds of Category B Building Roof (Side View) 


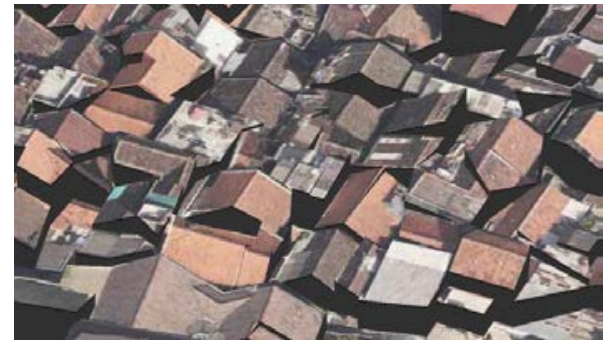

(a)

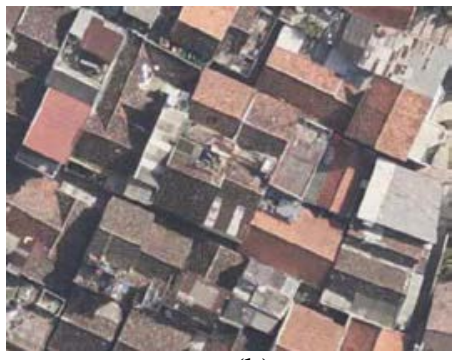

(b)

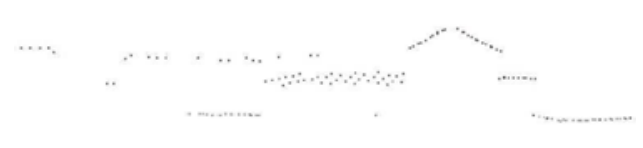

(d) (c)

Figure 18. (a) Sample Building Model in Category C. (b) Two Dimension Orthophoto of Category C. (c) Point Clouds of Category C Building Roof (Front View). (d) Point Clouds of Category C Building Roof (Side View)

\subsection{Generation of Digital Terrain Model}

DTM has been created from TIN model. TIN is created by connecting the data point clouds on ground class. Figure 20 illustrate TIN formation to create DTM.

\subsection{Overlay Result Between DTM, Building Model, and Orthophoto}

Figure 21, 22, 23, and 24 are show overlaying between models of buildings, land surface model, and orthophoto.

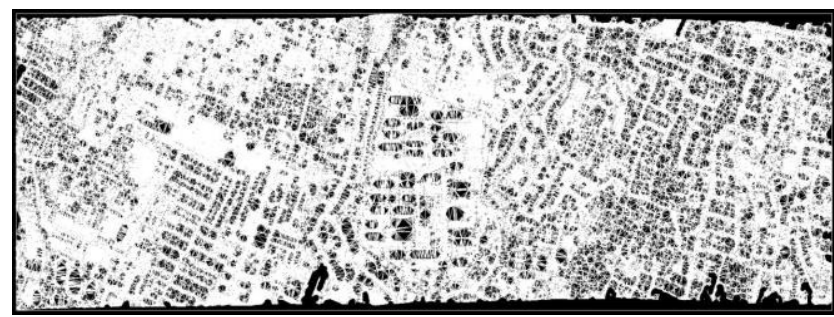

Figure 20. Terrain Model of Study Area

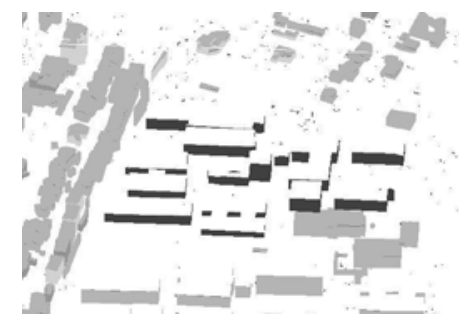

Figure 21. Overlay Between Building Model and Terrain Model

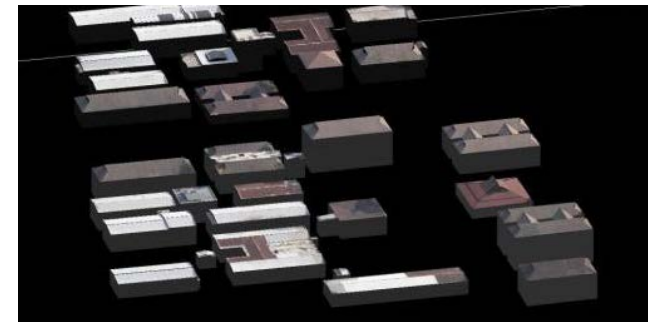

Figure 22. Overlay Between Building Model and Orthophoto

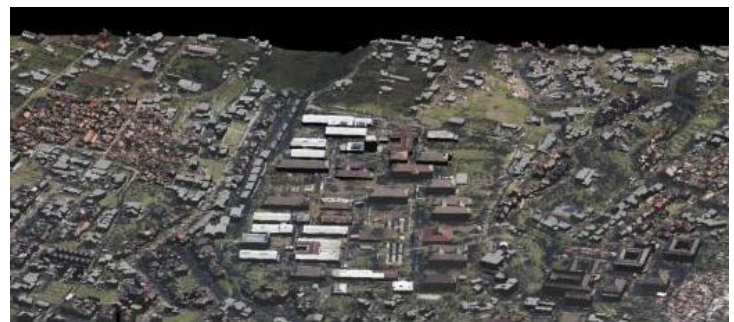

Figure 23. Overlay Between Building Model, Terrain Model, and Orthophoto in General View

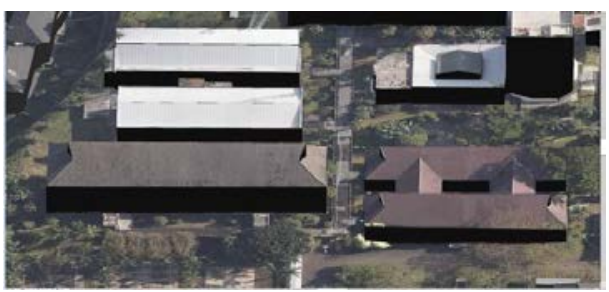

Figure 24. Overlay Between Building Model, Terrain Model, and Orthophoto in Detail View 


\subsection{Analysis}

From three categories of building model that successfully created. Building models in categories A, 30 building blocks can be modeled well without any broken specific section. Category B, 220 building blocks can be modeled well as in the example illustrated 21. Building models in category C in densely housing, some 428 building blocks not to be modeled well and seemingly broken in some parts of the model like in figure 25 . This is due to the image point clouds can not properly separating between one building to another, so the building models blend between one building block with other building blocks nearby.

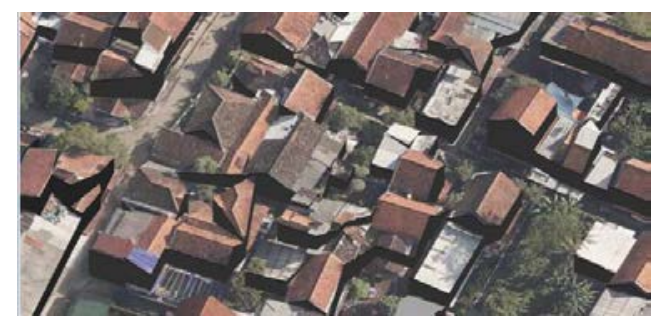

Figure 25. Illustration of Dense Housing Model

\subsection{Result of Building Model Accuracy Validation}

The accuracy of building models from LiDAR data can be validated with other data acquisition. In this case, the coordinates of building model compared to planimetric edge of the building which was formed from stereoplotting of aerial photographs referenced with LiDAR data. Table 2 shows the result of building the model accuracy with LIDAR data and stereoplotting. 3 buildings of category used to sample of test. The results of RMSEr is $0.715 \mathrm{~m}$. The error value due to the parameter extraction buildings is less fit. Further research is needed to determine the appropriate parameters in the model to extract the building.

Tabel 2. Result of Building Model Accuracy

\begin{tabular}{|c|c|c|c|c|c|c|c|}
\hline \multirow{2}{*}{ NO } & \multirow{2}{*}{ LABEL } & \multicolumn{2}{|c|}{ Ortofoto } & \multicolumn{2}{|c|}{ Model Bangunan } & \multirow{2}{*}{$\frac{\Delta \mathrm{X}}{(\mathrm{m})}$} & \multirow{2}{*}{$\begin{array}{c}\Delta \mathrm{Y} \\
(\mathrm{m}) \\
\end{array}$} \\
\hline & & $x(m)$ & $\mathrm{Y}(\mathrm{m})$ & $\mathrm{x}(\mathrm{m})$ & $Y(m)$ & & \\
\hline \multirow{4}{*}{ Bangunan 1 } & $\mathrm{p} 1$ & 784226,180 & 9239893,279 & 784225,685 & 9239892,400 & 0,4946 & 0,8789 \\
\hline & $\mathrm{p} 2$ & 784225,989 & 9239867,992 & 784225,409 & 9239867,723 & 0,5795 & 0,2691 \\
\hline & p3 & 784274,303 & 9239866,700 & 784274,983 & 9239867,118 & $-0,6809$ & $-0,4178$ \\
\hline & $\mathrm{p} 4$ & 784275,238 & 9239892,134 & 784274,997 & 9239891,839 & 0,2408 & 0,2950 \\
\hline \multirow{4}{*}{ Bangunan2 } & p5 & 784225,853 & 9239858,068 & 784226,191 & 9239859,149 & $-0,3380$ & $-1,0813$ \\
\hline & $\mathrm{p} 6$ & 784225,640 & 9239833,605 & 784225,738 & 9239834,534 & $-0,0972$ & $-0,9294$ \\
\hline & $\mathrm{p} 7$ & 784275,461 & 9239833,173 & 784275,550 & 9239833,903 & $-0,0887$ & $-0,7304$ \\
\hline & $\mathrm{p} 8$ & 784275,674 & 9239857,636 & 784275,840 & 9239857,857 & $-0,1665$ & $-0,2213$ \\
\hline \multirow{4}{*}{ Bangunan3 } & p9 & 784369,256 & 9239846,762 & 784368,759 & 9239847,114 & 0,4975 & $-0,3524$ \\
\hline & p10 & 784368,773 & 9239821,139 & 784368,430 & 9239821,294 & 0,3439 & $-0,1554$ \\
\hline & p11 & 784394,316 & 9239820,657 & 784394,098 & 9239820,931 & 0,2180 & $-0,2739$ \\
\hline & p12 & 784394,799 & 9239846,280 & 784394,367 & 9239846,858 & 0,4321 & $-0,5779$ \\
\hline \multicolumn{6}{|c|}{ Number of Check Points } & 12 & 12 \\
\hline \multicolumn{6}{|c|}{ Mean Error $(m)$} & 0,1196 & $-0,2747$ \\
\hline \multicolumn{6}{|c|}{ Standard Deviation $(\mathrm{m})$} & 0,3919 & 0,5538 \\
\hline \multicolumn{6}{|c|}{ RMSE $(\mathrm{m})$} & 0,3938 & \begin{tabular}{|l|}
0,5972 \\
\end{tabular} \\
\hline \multicolumn{6}{|r|}{ RMSEr (m) } & 0,7153 & 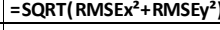 \\
\hline \multicolumn{6}{|c|}{ Horizontal Accuracy $(\mathrm{ACCr})$ at $95 \%$ Confidence Level } & 1,2381 & = RMSEr $\times 1.7308$ \\
\hline
\end{tabular}

\section{CONCLUSION AND SUGGESTION}

LIDAR data and orthophoto can create surface models with land and buildings. DTM and DSM of the data point clouds can produce a model. It can be concluded that the LIDAR data and orthophoto can create a threedimensional model of city building. The coverage area of this study is 222 hectare with 678 are the building blocks. As a result, model is divided into three categories based on the size and distance of proximity between one building to another. From the results, 250 buildings model which are in category A and B can be modeled very well and the rest of the category $\mathrm{C}$ it was unable to create a good building model or fracture appears on the model due to the building blocks of those area are too dense.

Three-dimensional objects above ground such as buildings, vegetation, electrical poles, or other required data density LiDAR about 6-7 points / $\mathrm{m}^{2}$ (Vosselman, 2001). This meant that the models created from these data can have a high accurately and suitability to approach its original shape like in reality. Orthophoto data required in order to validate the object in the field. Hopefully with this study could be a reference to other modeling threedimensional objects. 


\section{ACKNOWLDGEMENT}

The authors gratefully acknowledge to PT Karvak Nusa Geomatika for LIDAR data that was used in this research.

\section{REFERENCES}

A. P. McClunea, P. E. (2014). Automatic Urban 3D Building Reconstruction From Multi-Ray Photogrammetry. The International Archives of the Photogrammetry, Remote Sensing and Spatial Information Sciences, Volume XL-3, 219-226

Axelsson, P. (2000). DEM Generation from Laser Scanner Data Using Adaptive TIN Models. International Archives of Photogrammetry and Remote Sensing, Vol. XXXIII, Part B4., 110-117.

Beiser, L. (1992). Laser Scanning Notebook. SPIE.

Center, N. C. (2012). Lidar 101: An Introduction to Lidar Technology, Data, and Applications. Charleston: SC: NOAA Coastal Services Center.

Dipokusumo, B. S. (2010). DTM dan Interpolasi. Bandung: ITB.

Hough, P. (1962). Method and Means for Recognizing Complex Patterns. United States: U.S Patent 3.069.654.

J.M. Macay Moreira, F. N. (2013). From DSM To 3D Building Models: A Quantitive Evaluation. International Archives of the Photogrammetry, Remote Sensing and Spatial Information Sciences,, 213-219 Kim, K. a. (2011). Building Roof Modeling from Airbone Laser Scanning Data Based on Level Set Approach. ISPRS Journal of Photogrametry and Remote Sensing, 66(4):484-497.

Li, Z., Zhu, Q., \& Christopher, G. (2005). Digital Terrain Modelling : Principles and Methodology. New York: CRCPress.

LIDAR.ihrc.fiu.edu.(n.d.). Retrieved May 2, 2015, from http://LIDAR.ihrc.fiu.edu/images/schem_MD_MAN04_2.jp

Maas, H.-G., \& Vosselman, G. (1999). Two Algorithms for Extracting Building Models from Raw Laser

Altimetry Data. ISPRS Journal of Photogrammetry and Remote Sensing 54, 153-163.

Measures, R. (1984). Laser Remote Sensing. Krieger Publishing Company.

Morgan, M. a. (2000). Automatic Building Extraction from Airbone Laser Scanning Data. International Archives of Photogrammetry and Remote Sensing, 33(B3/2;PART 3):616-623.

Tack, F. G. (2012). 3D Building Reconstruction Based on Given Gound Plan Information and Surface Models Extracted from Spaceborne Imagery. ISPRS Journal of Photogrammetry and Remote Sensing, 67:52-64.

Vosselman, G. (1999). Building Reconstruction using Planar Faces in Very High Density Height Data.

International Archives of Photogrammetry and Remote Sensing, 87-92.

Vosselman, G. (2000). Slope Based Filtering of Laser Altimetry Data (Vol. XXXVIII). Amsterdam: IAPRS.

Vosselman, G. a. (2001). 3D Building Model Reconstruction from Point Clouds and Ground Plans. International Archives of Photogrammetry and Remote Sensing, Volume XXXIV-3/W4 Annapolis, MD, 22-24 Oct., 37-43.

Vosselman, G. a. (2001). Map Based Building Reconstruction from Laser Data and Images. Automatic Extraction on Man-Made Objects from Aerial and Space Images.

Vosselman, G. a.-G. (2001). Adjustment and Filtering of Raw Laser Altimetry Data. OEEPE Workshop on Airbone Laserscanning and Interferometric SAR for Detailed Digital Elevation Models, 11..

Wolf, P. R., \& Dewitt, B. A. (2000). Elements of Photogrammetry with Applications in GIS. United States: McGraw-Hill. 